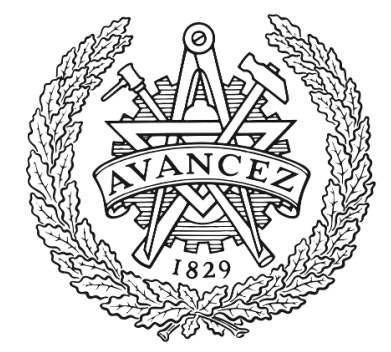

CHALMERS

UNIVERSITY OF TECHNOLOGY

\title{
Modelling the Roles of Designers and Teaching Staff when Doing Participatory Design with Children in Special Education
}

Downloaded from: https://research.chalmers.se, 2023-04-26 02:15 UTC

Citation for the original published paper (version of record):

Börjesson, P., Barendregt, W., Eriksson, E. et al (2018). Modelling the Roles of Designers and Teaching Staff when Doing Participatory Design with

Children in Special Education. Proceedings of PDC'18. http://dx.doi.org/10.1145/3210586.3210589

N.B. When citing this work, cite the original published paper. 


\section{Modelling the Roles of Designers and Teaching Staff when Doing Participatory Design with Children in Special Education}

\author{
Wolmet Barendregt \\ Department of Applied IT, University \\ of Gothenburg \\ Gothenburg, Sweden \\ wolmet.barendregt@ait.gu.se
}

Olof Torgersson

Computer Science and Engineering,

University of Gothenburg \& Chalmers

University of Technology

Gothenburg, Sweden

olof.torgerssson@cse.gu.se

\author{
Peter Börjesson \\ Computer Science and Engineering, \\ University of Gothenburg \& Chalmers \\ University of Technology \\ Gothenburg, Sweden \\ peter.borjesson@cse.gu.se \\ Tilde Bekker \\ Department of Industrial Design, \\ Eindhoven University of Technology \\ Eindhoven, The Netherlands \\ m.m.bekker@tue.nl
}

\author{
Eva Eriksson \\ School of Communication and \\ Culture, Aarhus University \& \\ Chalmers University of Technology \\ Aarhus, Denmark \\ evae@cc.au.dk \\ Helle Marie Skovbjerg \\ Lab Design for Play, Design School \\ Kolding \\ Kolding, Denmark \\ skovbjerg@dskd.dk
}

\begin{abstract}
In this paper we focus on the relational work when doing PD with children in special education as a hybrid practice, meaning that the designer aims to perform design activities with children in their own environment. Based on the experiences of a three-year project in a special education school, we first present a two-dimensional model for 'who participates with whom in what', describing the agency that the designer may need to both plan and execute design activities in relation to the teachers and the children. Thereafter, we relate those two dimensions to different kinds of authority that the designer might wish to have and avoid to have, and provide examples of the backstage work with children and teaching staff that may occur in order to gain the right kind of authority. Finally, we discuss the designer's relational work to balance the different kinds of authority and what may happen if there are mismatches between the different stakeholders' expectations about authority. While we are aware that it is not possible for a designer to precisely foresee how their presence in a special education school will play out, this paper aims to provide a critical reflection on our participatory practices which may help other designers to be prepared for the situations they may encounter in their own work in special education schools.
\end{abstract}

\section{CCS CONCEPTS}

- Human-centered computing $\rightarrow$ Participatory design;

Permission to make digital or hard copies of all or part of this work for personal or classroom use is granted without fee provided that copies are not made or distributed for profit or commercial advantage and that copies bear this notice and the full citation on the first page. Copyrights for components of this work owned by others than the author(s) must be honored. Abstracting with credit is permitted. To copy otherwise, or republish, to post on servers or to redistribute to lists, requires prior specific permission and/or a fee. Request permissions from permissions@acm.org.

PDC '18, August 20-24, 2018, Hasselt and Genk, Belgium

(C) 2018 Copyright held by the owner/author(s). Publication rights licensed to Association for Computing Machinery.

ACM ISBN 978-1-4503-6371-6/18/08 ..\$15.00

https://doi.org/10.1145/3210586.3210589

\section{KEYWORDS}

participatory design, children, teachers, special education, relationships, hybrid practice

\section{ACM Reference Format:}

Wolmet Barendregt, Peter Börjesson, Eva Eriksson, Olof Torgersson, Tilde Bekker, and Helle Marie Skovbjerg. 2018. Modelling the Roles of Designers and Teaching Staff when Doing Participatory Design with Children in Special Education. In PDC '18: Proceedings of the 15th Participatory Design Conference - Volume 1, August 20-24, 2018, Hasselt and Genk, Belgium. ACM, New York, NY, USA, 11 pages. https://doi.org/10.1145/3210586.3210589

\section{INTRODUCTION}

The involvement of adults in Participatory Design (PD) projects has a long tradition and has been examined extensively. The involvement of children in PD projects is a more recent development, which has received slightly less attention. Druin and her team were some of the very first to suggest that adult designers and children could have an equal partnership [7], and that children could be "equal stakeholders" or have an "equal voice" in the design process [19]. However, in most cases, the children in the projects described had a previous relationship to the adult designers, and the children were brought into the lab to work together with the designers. After years of working together in this way, it could be said that they had indeed developed a form of equal partnership. However, at least in Europe, many research projects involving children take place in a natural context for the children, e.g. at school or at home [12]. In this context, the designer does not have an existing relationship with the children, but there are already existing networks of relations between the children and the teaching staff [28]. Furthermore, both the children and teachers have expectations about the activities going on in this context, and the role they may play during these activities, which can lead to mismatches that the designer needs to be prepared for.

Several researchers have focused on designing with groups of heterogeneous actors. For example, Bødker et al. [4] have focused on the relationships between designers and different professionals involved in participatory design processes, and Light and Akama 
[15] have focused on designers working with groups of volunteers or people who are likely to face a future bushfire in the context of disaster mitigation. Taking a rather similar approach, this paper focuses on the triangle of relationships that are established and develop as designers work in a special education environment where both children and teaching staff are present, see Figure 1.

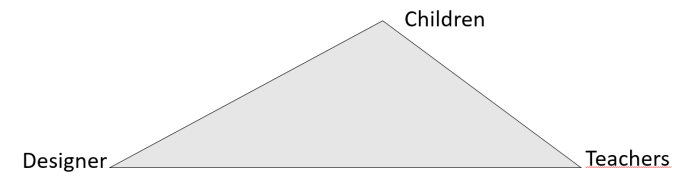

Figure 1: Triangle of Relationships

We first present a theoretical background in which we define this kind of situation as a hybrid practice. Thereafter, we present related work on doing ethnography and PD with children, and the role of the different adults during this process. Based on examples of activities during a three-year long project in special education, we then create a model of the kinds of activities designers and teachers can find themselves in together with the children, and present an explanation of what is going on in terms of different kinds of authority. Finally, we discuss the designer's relational work to balance the different kinds of authority and what may happen if there are mismatches between the different stakeholders' expectations about authority.

\section{THEORETICAL BACKGROUND}

When entering the special education environment, we assume that the designer is interested in performing different kinds of designrelated activities with the children. Muller's taxonomy of PD practices [23] shows that PD activities can range from the designer fully participating in the world that belongs to the users, to the users participating directly in the design activities. In this paper we focus on PD activities with children in their own school context where teachers and assistants are present, but where they are involved in activities where the designer is also present. The designer can have more or less agency (or influence), both in initiating activities and in the performance of the activities. Muller has coined practices that "turn out to occur in an uncertain, ambiguous, overlapping disciplinary domain that does not "belong" to either the software professionals or the end-users" as Hybrid Practices [22]. We therefore consider doing PD with children in their school a hybrid practice, even though it happens physically "on the user's turf", as is depicted in Figure 2. Just by being present in this context, the designer already influences what is going on.

When doing $\mathrm{PD}$ as a hybrid practice, we assume that the designer aims to initiate or participate in (design) activities in the context of the child. These design activities become part of a whole set of other activities that the children naturally participate in in this context, with or without the adults who are responsible for them. Approaching activities from the point of intersection between the sociocultural perspective (e.g. Lave and Wenger [14]) and Goffman's [10] perspective on social interaction, all actions, events, and utterances do not speak for themselves but, rather, depend on 2

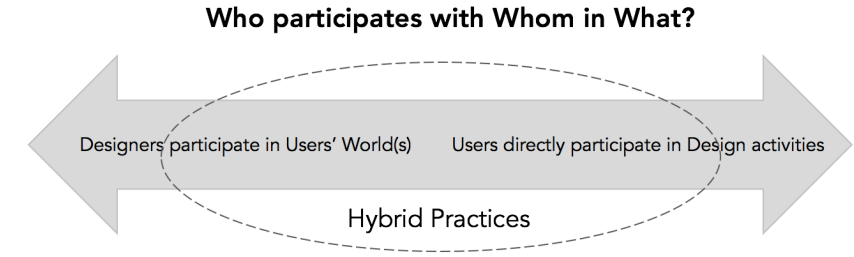

Figure 2: Who participates with Whom in What? Adapted from Muller [23] to include Hybrid Practices

how the participants have understood them, which in Goffman's terminology would be called framing. The more familiar people are with the components in a field of activities, the easier it is to act in them, which also implies that framing in activities is constrained by social structures and social organisations and that people have established standards for their behavior and role in those activities. In the case of a designer entering the child's context to do a PD project, children and the adults around them have a common understanding and expectations of the activities they usually perform and their behavior and roles in those activities [25]. A renegotiation of the activities and the participants' roles therein needs to occur when the researcher enters the scene and becomes a more or less active participant in the activities. In this process, power moves between different actors and social positions and is negotiated between children, researcher, and the adults taking care of the children [5], and it is likely that frame-conflicts - misunderstandings about what the activity is and the roles of all participants in this activity - will occur. For example, teachers present during a design workshop with children may think that their role is to guide the children towards a workable solution, while the designer is merely interested in the spectrum of ideas the children may have.

\section{RELATED WORK}

While several models have been developed to discuss the roles of children, adults and researchers/designers, both in ethnographic research and in PD, we claim that none of these models has fully covered the complex situation as described above. Fine and Glassner [8] have focused on the roles that researchers assume when they study children. Although their work is rooted in ethnography rather than the PD field, it is highly relevant as they aim to study children in their natural environment, as we do here. They state that researchers' roles in relation to the children may be differentiated on two relevant dimensions: (1) the extent of positive contact between the adult researcher and the children, and (2) the extent to which the researcher has direct authority over the child. This leads to the definition of four roles for the researcher, see Figure 3.

However, when doing PD with children there are different kinds of activities than just observing children, and the designer may want to adopt different roles depending on the kind of activity. In the context of PD, Yip et al. [30] have therefore defined four roles for adults that match the roles of children as previously defined by Druin [7]: users, testers, informants, and design partners. According to Yip et al. [30], when the child is a user, the adult is an observer, when the child is a tester, the adult is a test facilitator, when the 


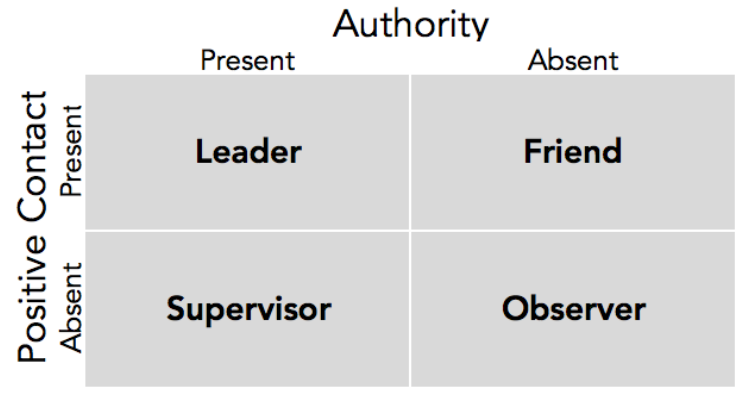

Figure 3: Relationship between the adult researcher and children according to Fine and Glassner [8]

child is an informant, the adult is an interpreter; and when the child is a design partner, the adult is also a design partner.

Depending on the kind of activity and the level of involvement of the children, the designer may thus adopt different roles. The paper by Yip et al. addressed the designers' roles in design activities based on the role of the participating children. However, it did not address the fact that, in many contexts, there are many other adults surrounding the children, such as teachers and assistants, who can play different roles in design activities.

Both Molin-Juustila et al. [21] and Benton and Johnson [2] have acknowledged the importance of other influential participants besides the children. Benton and Johnson identified five roles that adults (both designers and other adults) can play when doing design with children with special educational needs; they could be facilitators who clarify children's ideas; they could be motivators for children to participate in the session; they act as children's caregivers; they act as proxies who participate in design activities on children's behalf; and they are co-designers and design partners who generate individual ideas, scaffold children's brainstorming, and integrate ideas with the children. Benton and Johnson argued that similar roles could be played by adults in design activities with typically developing children.

Molin-Juustila et al. [21] also focused on the importance of other voices than the children's when designing with children. Based on previous literature they pointed out that children interact daily with adults, such as parents and teachers, and that adults are key actors in children's use of technologies. In their extensive literature review they also addressed the important role of the teacher, especially for gaining approval; determining the learning goals; ensuring that the design activities and language are appropriate, interesting and understandable for the children involved; and in data collection in the classroom. They acknowledged that the presence of a teacher may affect the design process in an undesired way and suggested several ways to avoid this negative influence, such as consciously avoiding authority, making sure that children and adults are both unfamiliar with the technology, involving the adults in a later phase of the design, or placing the activities outside the usual environment. In the analysis of six projects involving children, they focused on interaction order and historical body. Interaction order draws upon Goffman's idea of people behaving differently in different constellations. When working with children, this means that "the presence or absence of parents, teachers or researchers will have consequences for how interaction delicately builds up"[21]. Historical body refers to "the abstraction of people's social practices or repeated experiences in the course of their lives"[21]. According to Molin-Juustila et al. an example is that "children [...] become gradually socialised into school life, i.e., being school-pupils, learning appropriate behaviour in the classroom" [21].

The related research discussed above provides some insights in the intricacies of doing PD as a hybrid practice where children and adults are involved. Fine and Glassner [8] showed that the role of the researcher may be defined by the presence or absence of certain dimensions and Yip et al. [30] suggested an interdependency of roles by connecting the designer's role to the child's role. Neither of these two sources took the presence of other adults explicitly into account, although Fine and Glassner did state that " $[\mathrm{t}]$ he participant observer without formal authority must also gain rapport with adults, authorities, or guardians who are or potentially might be present". Benton and Johnson focused specifically on the roles that adults could play during the design with children, but they did not explicitly address the fact that all roles are connected to each other as Yip et al. did, and how designers and other adults may have to divide and negotiate their roles. Finally, Molin-Juustila et al. [21] addressed the fact that there may be many different voices besides those of the children.

In this paper we take a similar approach as Molin-Juustila et al. where we are explicitly aware of the fact that children, designers, and teaching staff all have voices in hybrid practices in the school context. However, based on examples from our project, we first try to define the elements that are important in such hybrid practices, working towards a general model of the roles the designers and teaching staff in special education can play in the activities with the children. Thereafter, we will discuss the role of different types of authority as well as the necessary backstage work in order to allow certain roles to appear. According to Dindler and Iversen [6], "a large part of work goes on backstage and between these events [...] these activities include the work that goes on to explore, create and consolidate working relationships". Finally, we discuss several examples of situations where there is a mismatch between all stakeholders' assumptions about their role or the other stakeholders' role in a certain activity. The aim with this paper is not to provide specific rules for how to behave in each of those situations. Rather, our aim is to provide a critical reflection on our participatory practices, as called for by Light and Akama [15], and help designers to "gain a deeper understanding of the relational expertise of the designer and to develop a language that supports a fruitful discourse on these matters" [6].

\section{OUR CASE}

\subsection{Data gathering}

We base this work on a three-year long project with the aim of developing touch-based technologies to help children develop their socioemotional skills. The project involved children from two classes in a special education school in Sweden. The first class included children between 10 and 12 years old, and the second class included children between 13 and 16 years old. During the second year of the project, the two classes were merged into one. The school that 
participated in the project was located in a high socio-economical area of [City]. At the start of each semester, we asked the parents of the children to sign an informed consent form, as required by the Swedish Research Council. In addition, before each workshop the purpose and different elements of the workshops were explained to the participating children, who were also reminded that participation was voluntary.

Special education in Sweden is its own school form, with its own curriculum, separate from the ordinary school. The school activities in special education should as much as possible correspond to ordinary school education. The children in special education are typically diagnosed with an Intellectual Disability, often co-occurring with conditions such as Autism Spectrum Conditions (ASC), Downs Syndrome, Cerebral Palsy, or Attention-deficit/hyperactivity disorder (ADHD), but are not grouped or divided based on those diagnoses. An important part of special education is that children are given individually adapted support based on their needs and abilities. This support can be provided by student assistants or personal assistants, helping the child during the school day.

The designer was a PDD student in Interaction Design who had gained access to the school through a previous research project working in close collaboration with one of the teachers. In the requirements gathering phase of the project, the designer spent on average one day a week in the school. During the later stages he returned to the school regularly over the course of the project to involve the children and teachers in different design and evaluation activities.

\subsection{Data analysis}

The data was collected in note form by the designer after each time involving the children in various PD activities in the school. In the first phase of data analysis for this paper, the designer consulted all field notes and extracted a large number of situations and activities in which role negotiation, confusion, and relational work possibly occurred. All examples were read by all authors in order to determine whether they really represented an aspect of the phenomenon, and whether they could be described in a common way, using overarching terms and concepts. This was a very iterative process, where different ideas were tested, and where we came up with new examples, and in some cases counterexamples from other projects, to see whether our description would hold. Finally, we came up with a model to describe the different forms of hybrid practices in a special education school context, and the factors that we think play a role in such activities, as will be described below.

\section{MODELING HYBRID PRACTICES IN A SPECIAL EDUCATION ENVIRONMENT}

In order to model hybrid practices in participatory design activities in a special education context, we have identified two relevant axes, see Figure 4. On the $\mathrm{x}$-axis, the designer is allowed more and more agency for the initiation of design activities within the school context. This axis can be described as dealing with 'Who participates with whom in what'. On the far left of this axis, the activity is initiated by the teacher as a normal school activity in which the designer can take part, while on the far right, the activity is initiated by the designer and the teacher can take part. On the y-axis, the designer receives more and more agency in relation to working with the children during an activity. This axis can be described as dealing with 'Who participates with whom in what' between the designer and the children. On the bottom, the designer merely observes the activity without much interference, while moving towards the top, the designer takes on a more active role, and at the top possibly even leads the activity, having a high level of agency within the activity. According to Del Gaudio et al. [9] agency "is an actor's capacity and possibility of action [... which is] determined by the power exercised by other actors". According to Lupia [16] "whoever delegates agency is the principal and whoever receives authority is the agent". While Del Gaudio et al. mainly discuss how designers delegate agency to local partners, in our context the delegation of power to act goes in both directions between the teachers and the designers. On the $\mathrm{x}$-axis, they negotiate the power to initiate activities in the school, while on the y-axis, they negotiate the power to influence the activities by interacting with the children. They are thus both principal and agent, because the teacher may delegate agency to the designer in relation to planning and executing school activities, while the designer may delegate agency to the teacher in relation to planning and executing design activities.

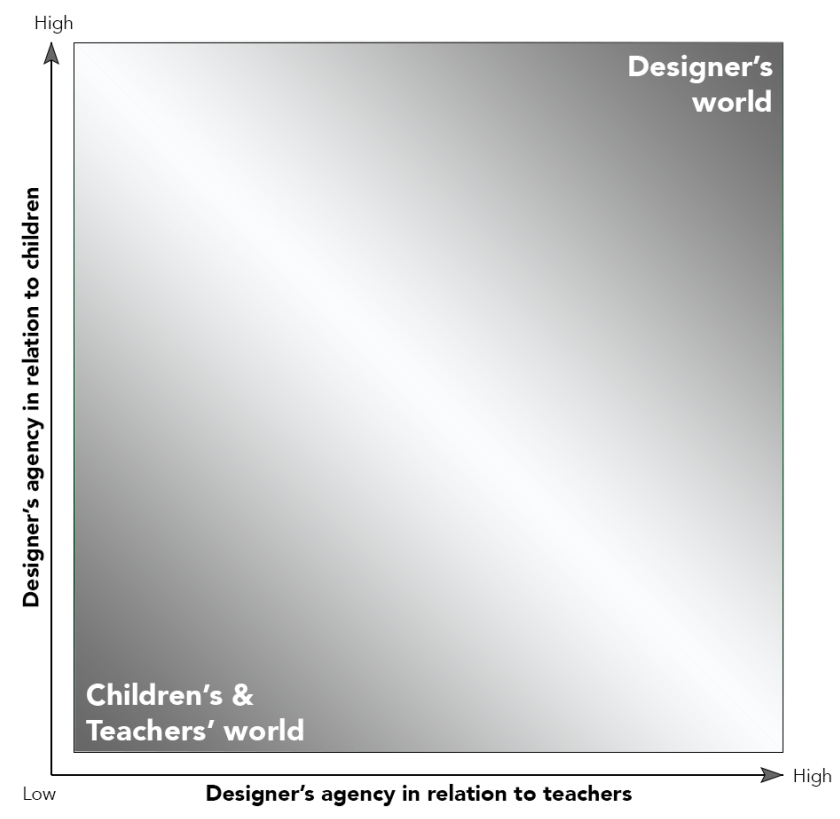

Figure 4: Our model using two axis for who participates with whom in what.

The model presented above is based on actual examples from our project, which will be explained in further detail below. Examples in the text are numbered in order to place them in the model towards the end of the section.

\subsection{Levels of Agency}

In a school context, the teaching staff is usually responsible for both planning and executing many activities with the children, meaning that they have a high level of agency in relation to the children. 
However, when a designer enters this context, some activities are more teacher-initiated while others become more designer-initiated. Within these teacher- or designer-initiated activities both the designer and the teacher can have more or less agency in relation to the children.

5.1.1 Teacher-initiated Activities. Teacher-initiated activities are activities that usually occur in the school, such as lectures. In a form coming closest to doing ethnographic work, the designer can observe the teacher and children during such activities to gain design knowledge while remaining rather passive. An example from our project was the following:

(1) Because I was interested in children's needs and requirements for touch-based applications to develop socio-emotional skills, I observed in the classroom during a class on 'relations and communication'.

However, during a teacher-initiated activity, the teacher can allow the designer more and more agency in relation to interacting with the children. In the following example, the teacher invited the designer to influence the activity in relation to the children a bit more by becoming an active participant:

(2) During a later class, the teacher asked me '[Name], do you know whether you have to bow for the king?'. After class he suggested that I could raise my hand if I wanted to get involved more.

An example of the designer being given even more agency happened during the third visit of the designer to the science class:

(3) Usually, the children were supported by one or two assistants. At the beginning of this class, one of the assistants came in to help the children. However, at this time, the teacher asked the assistant to go to one of the other classrooms because I was already there. I was invited by the teacher to help the children build their own wind-powered rocket.

Finally, we also found an example of the designer essentially leading a teacher-initiated activity.

(4) I had observed in class several times and had also assisted one group in ideation of a game. Now the children were about to start programming their games in Scratch, and I independently worked with one of the groups, where I explained things to them, careful not to do the task for them.

5.1.2 Designer-initiated Activities. Designer-initiated activities are activities that mainly occur because of the designer's presence. In a form coming closest to inviting children to the lab, the designer initiates and performs an activity in the school, rather independently of the teachers. An example from our project was the following:

(5) To understand how the children used technology together and what they thought about collaboration, I planned a design activity where the children tested several existing collaborative applications in pairs. Thereafter I engaged them in a group discussion about their likes and dislikes about the different applications.
However, even when the designer has the leading role, teaching staff is often involved to support e.g. the communication between the designer and children, or to reduce anxiety:

(6) As part of the evaluation, the children participated in a short interview about their use of the technology. During the interviews, some children were supported by one of the assistants who could strengthen the communication with the help of sign language, but also make the child more comfortable in the one-onone interview situation.

While in the examples above the designer is highly active in a design activity, it is also possible that the designer plays a more passive active role, in favour of the teacher's active participation.

(7) In order to understand children's design ideas for a collaborative game, I planned a design workshop where children in groups were asked to create a collaborative tablet game using pens and paper. During the activity, the children were supported by a teacher or an assistant. I walked around the different groups to make observations, give children feedback on their ideas, or ask them to explain something in more detail.

These last two examples are similar to how Benton et al. [3] describe the involvement of a familiar teacher in design activities to help incorporate children's interests, reduce their anxiety, and prompt for answers, but also to discourage negative behaviour and reinforce social behaviour.

Finally, we also encountered situations where the designer had very little agency in relation to the children, even though the activity was initiated by the designer. An example of this was the following:

(8) I planned a design activity where children were divided into two rooms and engaged in a group discussion about collaboration. The discussions in the two groups were led by two teachers. During the discussions I moved between the two rooms to make observations.

In practice this thus meant that the teacher facilitated the design activity, while the designer had a very passive role. Pardo et al. [24] involved teachers in a similar way when asking them to facilitate the evaluation of an educational technology with the children.

5.1.3 Truly Hybrid Activities. In the examples above we have made a distinction between teacher-initiated activities and designerinitiated activities. However, since the $\mathrm{x}$-axis in our model is a continuous axis, there may be activities that are truly hybrid activities. A first example from our project was the following:

(9) After the design activity was done, the teacher and I had a debrief and the teacher said she had nothing planned for after the break as she had assumed the workshop would last longer (even though I had sent her the time plan). The teacher suggested that we could keep exploring the theme of collaboration by asking the children to draw a picture together during art class.

Another example was when the designer and the teacher consciously determined which learning goals could be met during 


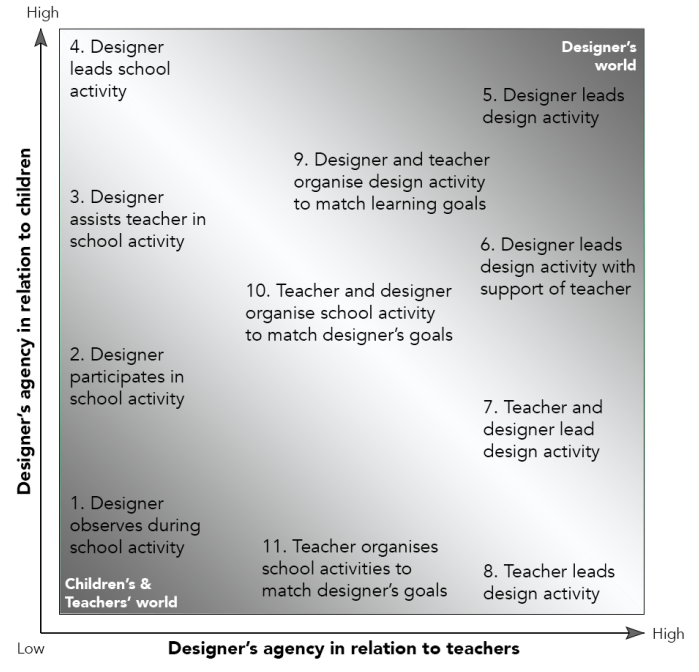

Figure 5: Numbered examples from the section above placed in the model

a design activity, and adapted it actively to include reflection on those learning goals:

(10) To make sure the design workshop would be suitable for the children, I planned it in collaboration with the teacher to decide upon e.g. the task, the tools and language used, as well as group composition and adult support. In addition, I brought up a number of possible learning goals for different school subjects (e.g. arts and crafts, language, and technology) that could be emphasized in different ways in the workshop. The learning goals were presented to the children in the introduction to the design activity, and the children were able to discuss what they had learned in a discussion held at the end of the workshop.

A similar situation can be found in a study by Millen et al. [20], where teachers were involved in creating and reviewing a method for involving children with autism in a design activity. To work with learning goals during design activities is argued for in [1].

Finally, we have an example of an activity that was initiated by a teacher to effectively prepare the children for a design activity:

(11) Before the design workshop, I communicated intensively with the teacher to make sure that the applications the children would be testing and the suggested outline of the workshop would be suitable for the children. In the workshop, the children would get to test different existing collaborative applications in pairs and then be engaged in a group discussion about their likes and dislikes with the different applications. As I showed up at school and started preparing for the workshop, the teacher said that the class had been practicing giving reviews on movies during the previous week in order to let the children give feedback on what they liked and disliked in the applications.
While the designer did not have any agency in relation to the children during this activity (the designer was not even present), he had a lot of agency in relation to the teacher, who initiated an activity almost on behalf of the designer.

5.1.4 Examples Placed in the Model. Figure 5 shows all examples described above on the two axes in our model. Although the model mainly focuses on the role of the designer in the activities, the role of the teacher is connected to the role of the designer. For example, when the teacher is present during a designer-initiated and -led activity, it is more likely that the teacher assumes an observing or assisting role, while the teacher probably has a facilitating or leading role when the designer acts more like an observer during the activity.

\section{WHERE DO THE DIFFERENT FORMS OF AGENCY COME FROM?}

\subsection{Agency in Relation to the Children}

The y-axis displays the designer's agency in relation to working with the children. On the bottom, the designer acts merely as an observer, leaving all agency to the teacher. On the top, the designer has a level of agency similar to a teacher, and can thus act rather independently of the teacher during an activity. Between the teacher and the designer, this is a form of power delegation where the teacher allows the designer to have more or less authority in relation to the children. Authority in an educational context (as well as in PD) is a controversial concept that is often regarded with suspicion. McLeod et al. [17] however, have tried to discuss authority in education in a more neutral way, referring to Wrong's [29] five types of authority: legitimate authority, competent authority, coercive authority, authority by inducement, and personal authority. Legitimate authority depends "upon the role occupied by a particular individual in a hierarchy" [17], meaning that children may obey a teacher because they are aware that that is what children in schools do. Competent authority "rests on a belief in the knowledge and skills of the authority"[17], and children may listen to their teacher because of the teacher's skills and knowledge. Coercive authority "relies on compliance based on the threat of the use of force" [17] while authority by inducement relies "on the ability of the person or institution expecting compliance to issue rewards"[17]. These two forms of authority are the most controversial because they are close to force and manipulation. Finally, personal authority "arises from a desire to please the teacher, rather than the fact the teacher is perceived to have powers, expertise or status endorsed by the school community" [17]. According to Wrong [29] this form of authority is more extensive and intense than the other forms, but also more unstable. Based on an attempt to implement a pupil empowerment program in a school for students experiencing (social), emotional and behavioural difficulties Sellman [26] concluded that according to the students "both the systems of reward and ultimately restraint were underpinned by the quality of relationships". Since teachers are the gatekeepers when it comes to the designer interacting with the children, the teachers have to feel assured that the designer has the right level and kind of authority, especially competence authority and personal authority. For example, a teacher will probably not allow a designer to lead a discussion with the children if 
he/she thinks that the level of personal authority of the designer is insufficient (e.g. the children feel uncomfortable with the designer). Based on this judgment, the teacher may also assume a certain role to assist the designer, for example to compensate for a lack of personal authority. Several of the roles for adults as identified by Benton and Johnson [2], such as the facilitator and caregiver role, can be defined as the teacher or assistant providing some kind of compensatory authority.

While a designer who enters the world of children, especially in a school context, will automatically have a certain level of legitimate authority from just being an adult [13], this form of authority may be associated with other more negative forms of authority, such a coercive authority. Designers may therefore need to work consciously to avoid those forms of authority [21] in order to create more equal levels of partnership. Christensen [5] points out that while children are very sensitive to differences between children and adults, it is possible to be "a different sort of adult", which requires a balance between acting as a responsible adult, while still maintaining the special position with the children. Guha et al. state that the goal is not to "[...] change all pre-existing adult/child relationships, merely the ones that exist in the context of the design process" [11].

\subsection{Agency in Relation to the Teachers}

As stated before, the designer's agency in relation to the teacher determines whether an activity is more teacher-initiated or more designer-initiated. According to Steutel and Spiecker[27] 'de facto' authority means that an "individual actually exerts a peculiar type of influence over other people's conduct or beliefs". This influence is caused by the fact that this individual claims to have a certain right, and that the person's claim is in fact accepted or acknowledged by those at whom it is directed. The designer's agency over the teacher's planning of activities in the school context can be seen as a kind of 'de facto' authority.

While the designer may have some legitimate authority because of e.g. a school leader having agreed to the designer's presence in the school, this is not always the case, and it is probably not sufficient for a good collaboration between the teacher and the designer. We argue therefore that the designer can only have 'de facto' authority if he/she has both some personal and competence authority in relation to the teacher.

\section{BACKSTAGE WORK}

In the examples discussed above, the designer often gained agency (or different forms of authority) in relation to the children and the teachers through earlier design activities. For example, while the researcher initially only observed during the 'relations and communication' class, he was invited to become a more active participant during later classes. However, we also observed a lot of relational work going on outside of the design activities, which could lead to agency. According to Dindler et al. [6] such relational work can be described as backstage work. Below, we will give several examples of backstage work related to both the children and the teachers that we observed during our project. However, even though we separate the two forms of backstage work here, we are aware that they are very much intertwined and sometimes hard to balance, as the following example shows:

After class, the head teacher and I talked about my observations during class before heading out to the school playground. As soon as I came out, a few of the children immediately grabbed me to come play with them. The girls took me for a short walk and talk, and I played football with them and some of the boys. Although I felt that it would have been good to continue to talking to the other teachers and assistants who were also outside during the break, I was often interrupted by the children who came to grab me to play again.

\subsection{Gaining Personal Authority with the Children}

As stated before, the designer already has some legitimate authority from being an adult. Therefore, the designer in our project put a great effort in creating a positive contact with the children by being present in different kinds of activities.

A few weeks into the fieldwork I still had not interacted a lot with the girls in class. Two of them rarely spoke in class, and a third girl was often very aware of my presence. She often looked over her shoulder to see where I was, struggling to do the task because of my presence. This changed one afternoon when I was invited by the teacher to join the class on a field trip to the town museum. As the children were putting on their shoes and jackets, this girl announced that she wanted to hold my hand and walk next to me to the bus. During the walk and the following bus ride, she asked me tons of questions: from what I had for breakfast, to what I and my children were going to do that afternoon. She often asked the same questions over and over again. Once we arrived at the museum, she stuck with me and barely left my side for the whole visit. The week after the field trip, the three girls in class, led by the girl from the museum visit, approached me to play during a break for the first time. I noticed that the two silent girls talked and interacted quite a bit among themselves, but they now also started to interact with me. First, we were going to play 'Princess Memory', but the girls changed their mind and wanted to play 'Red Light/Green Light instead. After that we played basketball, and I got to take part in their girls' cheer chant: "Oooooooooooooooooooh girls!"

The example above clearly shows the child's initial uneasiness towards the designer, which may be caused by the fact that he was an unfamiliar adult.

In some cases, the designer even consciously tried to avoid using certain forms of authority in order not to jeopardize the establishment of personal authority:

During my observations in class I often got to see what happened when the teachers turned their back 
towards a group of children or left the room briefly. The children would make faces or gestures towards each other, or they would switch from an educational application to some sort of entertainment application on the tablet they were working on. Sometimes, the children were not aware that I saw them and I could simply choose not to see it. Other times however, the children were aware that I saw them, and perhaps even tested me. At these occasions, I would often try to make the children aware that I had seen them, and that I thought what they were doing was uncalled for, but at the same time that I would not tell them to stop or report it further to the teacher.

In this example, although the designer had and was aware of his natural legitimate authority, he did not use any coercive authority to correct the children.

A similar example where the designer avoided coercive authority in order to establish personal authority was the following:

As the break started I was approached by a boy who asked if I wanted to join him to play football. We went to the football area that was located a bit to side of the main school building. As this area was out of sight from the rest of the school playground, there was usually an assistant present or keeping an eye on the children from a distance. After playing for only a few moments, two other children showed up and started hitting and spitting at the boy. I quickly looked around and realized there were no school staff close by, and it was up to me to stop the fight. After I had intervened and broken up the fight, I put my focus on talking to and comforting the boy, rather than focusing on the two troublemakers.

In this example, the designer had to use his legitimate authority as an adult to stop one of the children from getting hurt. However, once more, he merely focused on establishing personal authority with the boy. Although he could have corrected the other two children, he chose not to use coercive authority.

\subsection{Gaining Agency in Planning Activities with the Teachers}

At the same time as the designer tried to build up a relation with the children, he also had to negotiate agency with the teachers and assistants by establishing his personal and competence authority.

A first way for the designer to gain competence authority was by showing his interest for different school activities and by exemplifying how design activities could also be adapted to the school activities:

After class, the head teacher asked me if the content of the class was relevant to my research. I agreed but explained that I also wanted to take part in other classes, as well as as breaks and lunches. This got us talking about different ways of involving children in both school and design activities. As an example, the teacher asked if I had had any lab glasses they could borrow for a science class, to which I suggested that we could involve the children as co-researchers in a design activity with white coats and lab glasses. At the end of our conversation, the teacher said that any time I want to start conducting activities with the children he would be able to set aside some time in the schedule for that.

Another way to gain competence authority was by showing how his design skills and knowledge could be beneficial to the children:

During my observations in science class, the teacher showed a video about 3D printing for the children and discussed with them what one could do with that. After class I talked to the teacher and told him that I could bring some 3D-printouts from the university to the class to show the children. The teacher thought that this was a good idea, and the next time I showed some examples. The children were excited and discussed what they would like to print, ranging from Lego parts to personalized boxes. One child in particular got very excited when he realized he could print replacement parts for his $\mathrm{RC}$ car.

The designer could also gain competence authority was by showing that he was sensitive to the school values and prepared to adapt the design activities to those values:

Before the workshop, I was going through the final details with the head teacher. She told me how excited the children were and how they were looking forward to taking part in the workshop. As we looked through the papers with the informed consent that the teacher had collected, I realized we only had received informed consent for about half of the children. As I asked her about how we should proceed with respect to this she stated: "Everyone who wants to, should be allowed to take part". After explaining the importance of an informed consent, and discussing the matter with the teacher, we agreed to let everyone take part as it would be the most ethical thing to do, but without using their data. However, we formed two groups of children, one group in which all children had informed consent, and one group in which the children did not have informed consent. In addition, the teacher tried to reach the parents over phone, to ask them if this would be okay.

\subsection{Mismatches}

According to Del Gaudio et al. [9] "due to opening up the process, a design partnership in a PD process implies agency transfer and sharing among the partners". However, this can lead to 'agency loss' "when the designer is not able to negotiate this sharing and it happens in a higher amount than planned [...]". In our context, agency loss can happen in two directions: both when the designer and the teacher are unable to negotiate their sharing correctly. Although the designer in our project actively worked on gaining the appropriate kind of agency for the activities, our model also helped us to identify some situations in which there was a mismatch in the negotiation, leading to agency loss. We will here discuss several of those examples. 
First of all, since assistants come and go in the special education context, it could happen that the designer suddenly participated in a teacher-initiated activity without the assistant understanding the purpose of his presence.

At one occasion, I came to the school to learn that the head teacher had just become a father, and that a few of the regular assistants were sick. They were expecting four substitutes in total. Class was delayed and we waited for one of the regular assistants to come and cover for the head teacher. Finally, when the assistant came, she repeatedly made excuses towards me about not knowing how to use the smartboard and that she would not be using technology in class.

Without the designer having been able to explain the purpose of his presence during class, the assistant clearly showed discomfort, probably because she did not know what kind of authority he had.

In the following example, the designer had previously had a lot of agency when working with one group of children. However, when meeting a new group of children, the teacher did not make a correct assumption about the designer's agency in relation to this new group, meaning that the teacher gave the designer too much agency when working with the new group:

After having spent quite some time doing observations with the younger children during class, it was finally time to do some observations in the older children's class. While I was not a total stranger to these children, as we had met during some lunches and played a bit during breaks, it was the first time we met in class. The teacher in this class was the same as for the younger children. The teacher started the class by explaining that they would have a project during the spring in which they would make a game in Scratch, and the task for today was to come up with a concept for the game. The children were asked to form two groups, and one of the groups was asked to move into an adjacent room to brainstorm for ideas, while the other was asked to stay in the main classroom. The teacher then looked at me and asked: "[Name], could you go with that group, and help them? I'll stay here with this group". Both the children and I were rather surprised as we did not know each other very well. We first spent what seemed like a long time in silence, waiting to understand how to proceed. I had initially assumed that the group would be somewhat autonomous as they were seated in a room without a teacher or assistant present. However, the children seemed to look at me to get started. I thus suggested that they could think of some ideas for a game they would like to play. This brainstorming phase went slow at start and the children seemed reluctant to suggest ideas in front of me.

In this example, it was clear that the teacher assumed the existence of some personal authority that was not there. Although the designer was aware of his lack of personal authority, the children still looked at him for guidance, probably based on his legitimate authority as an adult, and the agency given to him by the teacher.
However, without having personal authority the children initially did not feel comfortable to make suggestions.

Finally, we would like to mention a situation where the teacher initially allowed the designer to initiate a design activity and lead it. Although the designer and the children agreed on the designer's authority, the teacher suddenly came in, assuming agency in the activity, which lead to confusion from the children's side:

The evaluation started with some informal talk and a warm-up activity in which the children could choose a name for their test team and pick an avatar from some cut-outs to glue on their team's box. Three girls were present without a teacher or assistant in the room. Two of the girls knew me well from previous activities, while the third was new, but happy to join the group. During the warm-up activity, the teacher suddenly entered the room and asked me if he could participate. I replied that he was welcome to take part but asked him to take a passive role as the goal of the main activity was to see if the children could understand the setup procedure of the game on their own. The teacher found this role quite challenging. When one of the girls suggested 'Teamwork' as a name for their team, the teacher immediately suggested the name 'TCCCP' (acronym of participants names), which one of the other children thought was great. In order for the girls' own idea to come through, I suggested to combine the names into 'Teamwork TCCCP'. During the evaluation of the game, the teacher immediately started instructing the children on what to do, e.g. "press that button", or "we need to choose a team together". For the next step, where the children needed to solve a puzzle, the teacher seemed to recall that he was supposed to have a more passive role and kept quiet. This however made the children very confused and they switched between looking at me and their teacher for instructions on what to do next.

This final example is rather similar to a situation mentioned by Mazzone et al. [18] where they explicitly had to instruct the psychologists within the design sessions with teenagers with behavioural problems "to not intervene and to avoid trying to help the pupils deal with their emotions during design activities", as the design activity focused on emotional issues. As Gaudio et al. [9] state, our situation was a form of 'designer agency loss' where the designer was not prepared for an agency transfer and the design partner was not acting according to the project's main aim, namely to give the children an equal voice. Of course, this is a reality in a school context given the teacher's usual agency when working with children. Although we need to deal with this reality, it might be beneficial for the designer and the teacher to engage more in discussions about the underlying values of PD, so that children's voices can be heard, even in the presence of a teacher.

\section{DISCUSSION AND CONCLUSIONS}

Muller highlighted the hybrid realm between the two distinct work domains of the software professionals and the end-users, and argued that the participatory practices that fall in this in-between 
domain, or third space, are a good place to look for new insights and understandings, and for syntheses of diverse forms of knowledge to spur ideas for products and work practices [22]. We argue that doing PD in the context of the special education school is such a hybrid practice, where the designer, children, and teaching staff are involved in design activities, requiring a negotiation of relationships. Based on many examples from a three-year project, we have developed a model describing who participates in what with whom on two axes: agency of the designer in relation to the children, and agency of the designer in relation to the teacher. We have argued that these levels of agency can be related to different forms of authority, especially personal authority, but also competence authority. We have also given several examples of the backstage work that may take place to establish these kinds of authority. Finally, we have used our model to discuss several examples of mismatches in roles.

At a quick glance, the reader could conclude from our model that we think that designers should strive for the highest levels of agency, and thus authority, being able to initiate and lead design activities. Although this may avoid some problems with agency loss from the designer's perspective, e.g. the teacher's voice being so present that the children's voices cannot be heard, we actually think that activities towards the middle of the model (truly hybrid activities) may be the most beneficial for mutual learning, especially between the teacher and the designer. Furthermore, we think the teachers' presence is a reality. As Bødker et al. [4] have suggested "PD work is not only about project achievements, but also about putting an organization in a position where experiences may be used beyond the project's end". Only by working with teaching staff on preparing design activities with children, and sharing the responsibility to carry out the activities with the children, the designer can empower teachers to make use of the project experiences later on. While this paper has mainly focused on how (design) activities were initiated and led in our project, we do intend to interview the teachers, assistants, and children who participated in the project during the past three years to find out what the sustained benefits of participation have been and how they have experienced the negotiation of agency.

The main limitation of this paper is that our model is based on examples from a single project. Therefore we cannot claim that it holds for all special education contexts. However, we do think the model is general enough to cover many different situations, even though some situations, like the designer leading a teacherinitiated activity, will never occur in certain projects. We also think that different forms of authority can be used effectively to reflect on the kind of backstage work the designer needs to undertake and what mismatches can occur. We thus encourage others to think about their own design activities in special education schools and see where they can be placed in the model, or how they can consider the role that authority plays in these activities.

Although this paper focuses on designers, teachers and children in a special education school context, we think that many of our observations may also apply to hybrid practices with other user groups in their own environment, such as families with children, or older adults in a care home. During our analysis, we have often discussed situations from other design projects in schools with typically developing children and found that a similar model may be 10 applicable; we could easily place the activities during these projects in the model. However, we also acknowledged that establishing personal authority in many cases seemed to happen without the designers consciously doing a lot of backstage work. We argue that in special education the efforts of the designer to establish personal authority may take some more time and therefore may be more visible than in schools with typically developing children, but that the same mechanisms may apply. Indeed, designers working with children in regular education may sometimes be tempted to draw the children completely into their world because of the ease of gaining authority, thereby missing the opportunities for mutual learning that may arise from truly hybrid practices.

Finally, we are aware that some people may be offended by the use of the word 'authority' in the context of doing PD with children. However, when working in a special education school context, on projects where the designer is the initiator of the contact and where children are often required to participate in activities, we think authority does play an important role. By distinguishing different forms of authority, we hope we have been able to express that we are indeed talking about a more equal form of relationship where children are empowered.

\section{ACKNOWLEDGMENTS}

The work presented in this paper is part of the Touch-AT project funded by the Marcus and Amalia Wallenberg Foundation under grant (MAW 2013.0063). We would like to thank all the people involved in this research over the past years.

\section{REFERENCES}

[1] Wolmet Barendregt, Tilde M. Bekker, Peter Börjesson, Eva Eriksson, and Olof Torgersson. 2016. Legitimate Participation in the Classroom Context: Adding Learning Goals to Participatory Design. In Proceedings of the 15th International Conference on Interaction Design and Children (IDC '16). ACM, New York, NY, USA, 167-174. https://doi.org/10.1145/2930674.2930686

[2] Laura Benton and Hilary Johnson. 2015. Widening participation in technology design: A review of the involvement of children with special educational needs and disabilities. International fournal of Child-Computer Interaction 3, Supplement C (2015), 23 - 40. https://doi.org/10.1016/j.ijcci.2015.07.001

[3] Laura Benton, Hilary Johnson, Emma Ashwin, Mark Brosnan, and Beate Grawemeyer. 2012. Developing IDEAS: supporting children with autism within a participatory design team. In Proceedings of the 2012 ACM annual conference on Human Factors in Computing Systems - CHI '12. ACM Press, New York, New York, USA, 2599-2608. https://doi.org/10.1145/2207676.2208650

[4] Susanne Bødker, Christian Dindler, and Ole Sejer Iversen. 2017. Tying Knots: Participatory Infrastructuring at Work. Computer Supported Cooperative Work (CSCW) 26, 1 (01 Apr 2017), 245-273. https://doi.org/10.1007/s10606-017-9268-y

[5] Pia Haudrup Christensen. 2004. Children's Participation in Ethnographic Research: Issues of Power and Representation. Children and Society 18, 2 (2004), 165-176. https://doi.org/10.1002/chi.823

[6] Christian Dindler and Ole Sejer Iversen. 2014. Relational Expertise in Participatory Design. In Proceedings of the 13th Participatory Design Conference: Research Papers - Volume 1 (PDC '14). ACM, New York, NY, USA, 41-50. https: //doi.org/10.1145/2661435.2661452

[7] Allison Druin. 2002. The role of children in the design of new technology. Behaviour and Information Technology 21 (2002), 1-25.

[8] Gary Alan Fine and Barry Glassner. 1979. Participant Observation With Children. Urban Life 8, 2 (1979), 153-174. https://doi.org/10.1177/089124167900800203 arXiv:https://doi.org/10.1177/089124167900800203

[9] Chiara Del Gaudio, Carlo Franzato, , and Alfredo J. de Oliveira. 2016. Sharing Design Agency with Local Partners in Participatory Design. International fournal of Design 10, 1 (2016), 53-64.

[10] Erwing Goffman. 1974/1986. Frame analysis: An essay on the organization of experience. Northeastern University Press, Boston, MA.

[11] Mona Leigh Guha, Allison Druin, and Jerry Alan Fails. 2013. Cooperative Inquiry revisited: Reflections of the past and guidelines for the future of intergenerational co-design. International fournal of Child-Computer Interaction 1, 1 (jan 2013), 14-23. https://doi.org/10.1016/j.ijcci.2012.08.003 
[12] Janne J. Jensen and Mikael B. Skov. 2005. A Review of Research Methods in Children's Technology Design. In Proceedings of the 2005 Conference on Interaction Design and Children (IDC '05). ACM, New York, NY, USA, 80-87. https://doi.org/ 10.1145/1109540.1109551

[13] Marta Laupa and Elliot Turiel. 1986. Children's Conceptions of Adult and Peer Authority. Child Development 57, 2 (1986), 405-412. http://www.jstor.org/stable/ 1130596

[14] J. Lave and E. Wenger. 1991. Situated Learning: Legitimate Peripheral Participation. Cambridge University Press. https://books.google.se/books?id=CAVIOrW3vYAC

[15] Ann Light and Yoko Akama. 2012. The Human Touch: Participatory Practice and the Role of Facilitation in Designing with Communities. In Proceedings of the 12th Participatory Design Conference: Research Papers - Volume 1 (PDC '12). ACM, New York, NY, USA, 61-70. https://doi.org/10.1145/2347635.2347645

[16] Arthur Lupia. 2001. International Encyclopedia of the Social and Behavioral Sciences 5. Elsevier Science Limited, Oxford, UK, Chapter Delegation of Power: Agency Theory, 3375-3377.

[17] Gale Macleod, James MacAllister, and Anne Pirrie. 2012. Towards a broader understanding of authority in student-teacher relationships. Oxford Review of Education 38, 4 (2012), 493-508. https://doi.org/10.1080/03054985.2012.716006 arXiv:http://dx.doi.org/10.1080/03054985.2012.716006

[18] Emanuela Mazzone, Janet C Read, and Russell Beale. 2008. Design with and for Disaffected Teenagers. In Proceedings of the 5th Nordic Conference on Humancomputer Interaction: Building Bridges (NordiCHI '08). ACM, New York, NY, USA, 290-297. https://doi.org/10.1145/1463160.1463192

[19] Brenna McNally, Matthew Louis Mauriello, Mona Leigh Guha, and Allison Druin 2017. Gains from Participatory Design Team Membership As Perceived by Child Alumni and Their Parents. In Proceedings of the 2017 CHI Conference on Human Factors in Computing Systems (CHI '17). ACM, New York, NY, USA, 5730-5741. https://doi.org/10.1145/3025453.3025622

[20] Laura Millen, Sue Cobb, and Harshada Patel. 2011. A method for involving children with autism in design. In Proceedings of the 10th International Conference on Interaction Design and Children - IDC '11. ACM Press, New York, New York, USA, 185-188. https://doi.org/10.1145/1999030.1999057

[21] Tonja Molin-Juustila, Marianne Kinnula, Netta Iivari, Leena Kuure, and Eija Halkola. 2015. Multiple voices in ICT design with children - a nexus analytical enquiry. Behaviour \& Information Technology 34, 11 (2015), 1079-1091. https://doi.org/10.1080/0144929X.2014.1003327 arXiv:http://dx.doi.org/10.1080/0144929X.2014.1003327

[22] Michael J. Muller. 2003. The Human-computer Interaction Handbook. L. Erlbaum Associates Inc., Hillsdale, NJ, USA, Chapter Participatory Design: The Third Space in HCI, 1051-1068. http://dl.acm.org/citation.cfm?id=772072.772138

[23] Michael J. Muller, Daniel M. Wildman, and Ellen A. White. 1993. Taxonomy of PD Practices: A Brief Practitioner's Guide. Commun. ACM 36, 6 (1993), 26-28. http://dblp.uni-trier.de/db/journals/cacm/cacm36.html\#MullerWW93

[24] Sofia Pardo, Frank Vetere, and Steve Howard. 2006. Teachers' involvement in usability testing with children. In Proceeding of the 2006 conference on Interaction design and children - IDC '06. ACM Press, New York, New York, USA, 89-92. https://doi.org/10.1145/1139073.1139097

[25] Janet C. Read, Peggy Gregory, Stuart MacFarlane, Barbara McManus, Peter Gray, and Raj Patel. 2002. An investigation of participatory design with childreninformant, balanced and facilitated design. In Proceedings of Interaction Design and Children International Workshop (IDC '02).

[26] Edward Sellman. 2009. Lessons learned: student voice at a school for pupils experiencing social, emotional and behavioural difficulties. Emotional and Behavioural Difficulties 14, 1 (2009), 33-48. https://doi.org/10.1080/13632750802655687 arXiv:http://dx.doi.org/10.1080/13632750802655687

[27] Jan Steutel and Ben Spiecker. 2000. Authority in Educational Relationships. Journal of Moral Education 29, 3 (2000), 323-337. https://doi.org/10.1080/ 03057240050137373 arXiv:http://dx.doi.org/10.1080/03057240050137373

[28] Lucy Suchman. 2002. Located Accountabilities in Technology Production. Scand. f. Inf. Syst. 14, 2 (Sept. 2002), 91-105. http://dl.acm.org/citation.cfm?id=782686. 782694

[29] Dennis H. (Dennis Hume) Wrong. 1995. Power : its forms, bases, and uses (3rd ed ed.). New Brunswick, N.J. : Transaction Publishers. Originally published: New York : Harper and Row, 1979. With new introd.

[30] Jason C. Yip, Kiley Sobel, Caroline Pitt, Kung Jin Lee, Sijin Chen, Kari Nasu, and Laura R. Pina. 2017. Examining Adult-Child Interactions in Intergenerational Participatory Design. In Proceedings of the 2017 CHI Conference on Human Factors in Computing Systems (CHI '17). ACM, New York, NY, USA, 5742-5754. https: //doi.org/10.1145/3025453.3025787 